Beneath the chart are spaces in which the pulse and respiration rates, the amount of urine passed, the specific gravity of the urine, and the presence of albumin or sugar may be duly recorded. "No. 2 " is in a form that may be conveniently used by the nurse when making the daily records. The medical practitioner in attendance on the case is able to see at a glance the progress or the reverse that has been made since his last visit. The charts are of a convenient size and will be found useful more particularly in general practice.

An Examination of the Condition of Primary Sohools in Dublin in 1905. By Sir CharLes A. OAMEron, C.B., M.D. R.U.I., \&c. Dublin : Printed by John Falconer. 1905. Pp. 37.-This short pamphlet contains details of the results of an examination of 174 national schools. "The primary schools under the management of the Christian Brothers and the Church Education Society were not examined as yet." The report states that though many schools are up to a high standard from a sanitary point of view, yet a much larger number are far from being in a satisfactory condition. From p. 8 the report consists of tabular matter giving details as to the name of the school, whether for boys, girls, or infants, the average number of attendances, the cubic space and floor space per pupil, the drainage, the sanitary accommodation, and other matters. The various defects, where existing, can thus be clearly seen by the authorities of the schools in question and we may echo Sir Charles Cameron's hope that "this examination of schools will be the means of causing many of these defective conditions to be remedied."

Catherine Grace Looh, R.R.C.: A Memoir. With an Introduction by Lord RoBerTs. London : Henry Frowde. 1905. Pp. 355. Price 4s. net. - This unpretending little work will be read with interest by all medical men and more especially by two classes of them-namely, officers of the Indian Medical Service and St. Bartholomew's Hospital men. All medical men who were at that hospital from about 1882 to 1887 will recollect "Sister Darker" and how admirable a sister she was. Miss Loch was born in 1854 and was trained as a nurse at the Royal County Hospital, Winchester. She went to St. Bartholomew's Hospital in 1882 and in 1888 left for India as one of the lady superintendents of the newly formed Indian Nursing Service. Her companions were another superintendent and eight nursing sisters. The reforms which the formation of the nursing service effected are, it would appear, comparable to those brought about in the Crimea by the arrival of Florence Nightingale and her devoted helpers, at least as regards the removal of "red tape" restrictions. The main portion of the book is occupied with selections from Miss Loch's journals and there is an appendix containing papers on various subjects connected with nursing written by her, together with appreciations from those who knew her. She died from cerebral hæmorrhage in 1904. The book is a worthy record of a bright, intelligent, earnest.minded woman.

Official Year-Book of the Scienlific and Learned Sooieties of Great Britain and Ireland, 1905. London: O. Griffin and Son, Limited. 1905. Pp. 309. Price 7s. 6d.- This volume is a record of the work done in science, literature, and art by various societies and Governmenc institutions during the session 1904-05. It is valuable for reference, for in its pages can be seen at a glance what papers were read, what subjects were dealt with, and who were the persons working in the different branches of science, literature, or art. Among the many year-books this, from our special point of view, is one of the most useful.

The Oxfurd Year-Book and Directory, 1906. London: Swan $_{a}$ Sonnenschein and Co., Limited. Pp. 764. Price 5s. net.-This is a work of reference which will certainly appeal to Oxford men. It is, of course, extremely difficult in a book of this kind to keep all the entries up to date and from a casual examination of sundry names in this edition we notice that a good many of them are not accurate as regards present conditions. On the whole, though, the book will be found useful.

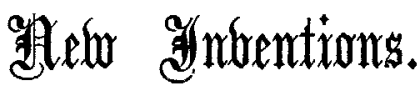

\section{AN IMPROVED DENTAL ELEVATOR.}

WITH a view to economising time as well as avoiding the inconvenience of changing instruments I have designed the double blade elevator shown in the accompanying illustration. It is a combination of the well-known right or left curved elevators and possesses the advantages of both these instruments. I have had an elevator of this pattern in use

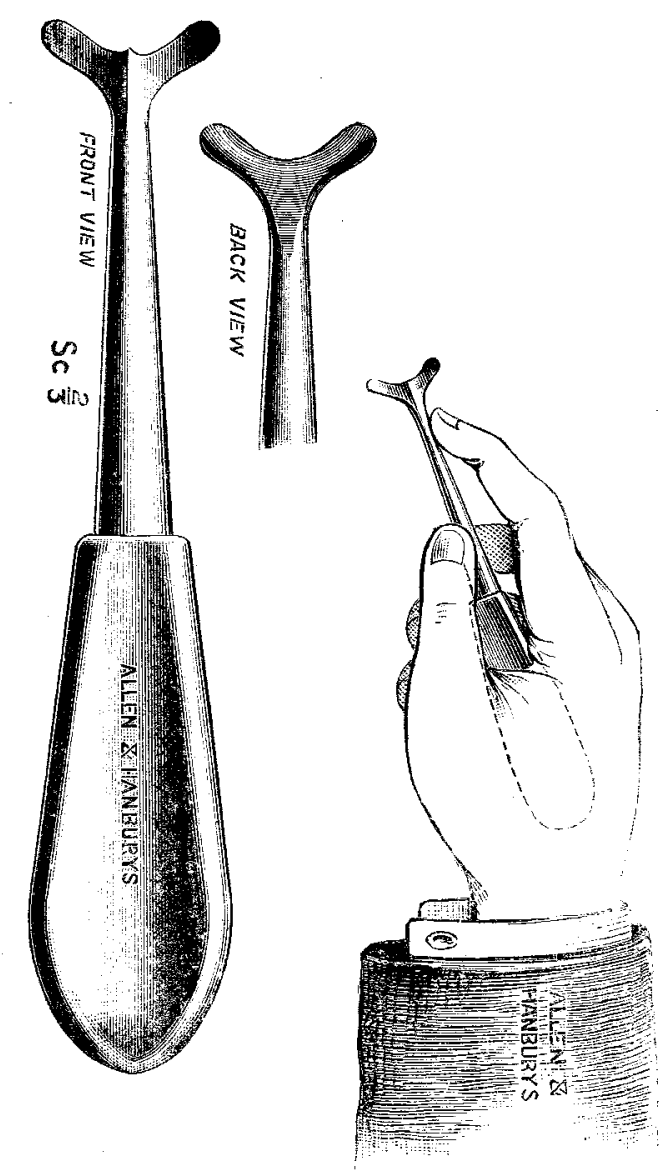

for some two years in hospital and private practice and have found it most useful in cases in which a number of dental extractions had to be performed in a minimum of time and with a minimum of instruments. For purposes of description I call it a "fish-tail" elevator. It is manufactured by Messrs. Allen and Hanburys, Limited, 48, Wigmore-street, London, W.

Assistant Dental Surgeon to King's College Hospitsl. Queen Anne-street, W.

\section{LITHOTOMY STRAPS.}

AN improved set of lithotomy straps designed by me is made of strong white webbing; the straps have running loops for applying just above the ankles, with a sliding buckle on the outside of each leg. The other end of these ankle straps is attached to the neck strap by means of a buckle. The neck strap passes round the patient's neck in the same way as a Clover's crutch, viz., one end over and the other under the shoulders respectively. The leg buckle being a sliding one permits the ankle loop to alter in size to fit any leg, whilst the neck strap can be made to pull the legs up to the required tension. The patient is placed in the lithotomy position and by means of these straps the legs are kept well apart, and more so if 
the patient is under an anæsthetic. There is no bar to interfere with urethral instruments. They are compact and easily sterilised. They are made by Messrs. Cuxson, Gerrard, and Co., Corporation-street, Birmingham, and cost $5 s$. the set. Thomas Young SImpson, M.B., B.S. Durh.,

Plymouth M.R.C.S. Eng., L.R.C.P. Loná.

\section{A NEW SPLINT FOR COMPOUND FRACTURES OF THE HUMERUS.}

THE illustration given below is that of a modified angular arm splint adapted for application to the anterior surfaces of the upper and fore arm, whilst allowing the latter to be held midway between supination and pronation, i.e., in the most comfortable position. By its use accurate apposition of the fragments may be continuously maintained in such severe compound fractures of the humerus as involve the onter and inner aspects of the upper arm at once, and

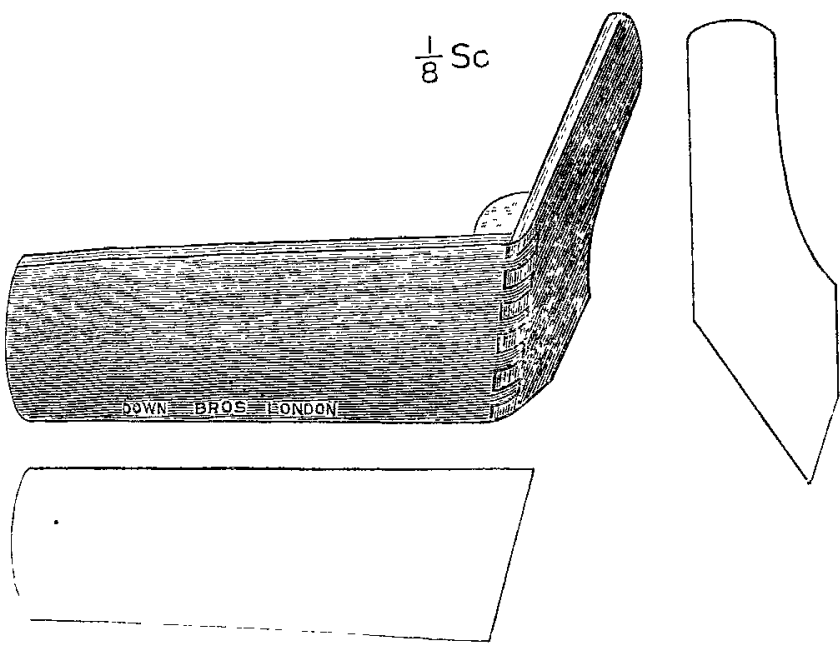

which thereby entail the removal of an internal or external angular splint and consequent disturbance of the parts when dressing the wounds. The idea can be easily carried out by an amateur carpenter and as I have found it most useful in such a case it may possibly be of some help to others in similar emergencies. It is made wider than usual to allow of firm bandaging without producing venous congestion, a point neglected in many splints. Both a right and left pattern are, of course, necessary. It has been made for me by Messrs. Down Brothers.

Nottingham.

ALEx. R. TwEEdIE, F.R.C.S. Eng.

\section{LEPROSY IN NEW SOUTH WALES.}

THE report of the Board of Health on leprosy in New South Wales for the year 1904 was issued on Oct. 31st, 1905. During 1904 eight cases of leprosy were admitted, making, with those remaining in the lazaret from the previous year, 18 in all; of these one leper died during 1904, leaving on Dec. 31st, 1904, 17 lepers under treatment; of these 13 were whites and four were coloured lepers. The total number of lepers admitted into the lazaret since it was opened in 1883 amounts to 96 ; of this number 44 were whites and 52 were coloured lepers. It must, however, be noted in this connexion that it is only since 1890 that the notification of leprosy has been compulsory in New South Wales and the detention of lepers made lawful. During the 22 years (1883-1904) the several admissions were distributed according to years as follows : 5, 2, 2, 3, 1, 4, 2, $2,10,12,7,5,3,3,2,4,1,1,8,1,10$, and 8 . These numbers serve to show the chronicity and persistency of leprous infection in an infected area and the slight tendency to a rise and fall of the numbers of lepers in a given district. The youngest leper admitted was a schoolboy, aged 13 years, born in Fiji of European descent; the oldest leper on admission was an English seaman, aged 75 years. The occupations of the lepers before admission were various, no trade seemingly predominating and almost all trades being fairly represerted.

The analysis of cases by Dr. J. Ashburton Thompson, the President of the Board of Health, which were admitted during 1904 is interesting reading.
CAsE 88.-A married female, aged 19 years, a native (European) of New South Wales; her father was admitted into the lazaret in 1890. The girl had lived during the first five years of her life in the same abode as her leprous father. The girl's mother, brotbers, and sisters, husband and child (aged one year) were not lepers.

CASE 89. - A female, aged 17 years, born in Sydney, New South Wales, of European parents. She had worked for two months at a box factory and for three weeks at a printer's. Neither of her parents nor her brothers and sisters were leprous, nor were any relatives or neighbours with whom the girl associated leprous.

CAsE 90.-A male, aged 54 years, a teamster, born at Botany, New South Wales, of European parents. At the age of 20 years he travelled round the State with elephants, otherwise he always lived at Botany. For seven years before becoming leprous he worked as a carter, carrying hides from the abattoir. Neither his wife nor any of his five children were leprous. The source of the infection was unknown.

CAsE 91.-A male, aged 24 years, a laundryman. This patient was a Chinaman; he had been three years in Sydney before becoming leprous.

CAse 92.-A male, aged 35 years, a labourer in the cane fields. He was a native of New Hebrides. He arrived in Queensland 15 years ago. He was acquainted with other lepers.

CASE 93.-A male, aged 65 years, a soldier. He was a native of England. He was married; he had nine children, none of whom were leprous. He had been stationed at Ceylon and New Zealand and went to live in New South Wales in 1866.

CASE 94.-A male, aged 32 years, a Chinese labourer. $\mathrm{He}$ had lived in New South Wales several years previously to the attack.

CASE 95.-A male, aged 23 years, a house painter, born in New South Wales, of European parents. He served in South Africa as a soldier in the cavalry ; whilst in Johannesburg in 1902 he noticed first symptoms of leprosy. Neither father or mother nor any one of his six brothers and sisters was leprous.

These cases admitted during 1904 serve to indicate the history of the persons suffering from leprosy who have been admitted in the lazaret since 1883. The proportion of persons of European descent or actually born in Europe who have developed leprosy in New South Wales is very large and it would seem that in no part of the British Empire are so many white people attacked by leprosy relatively to the population as in the Antipodes. The cause of this is unknown, nor is there any known means of ascertaining the cause; for the medium of communication and the extra-corporeal life of the bacillus lepræ are as yet unascertained. That the infection is apparently communicable from parent to child is occasionally the case, but there is nothing of the nature of proof that it is so. That the disease is conveyed by contact with any animal or by engaging in any trade or pursuit is likewise not proven. The development of cases seems so sporadic yet so persistent in some localities that a focus of infection would seem likely, but what that focus is or how the disease is spread therefrom is equally a mystery at present.

What is described in the report as the Lismore group of cases would seem to indicate family contamination, for the proofs that the members of the family lived together or that some of them had ever met for several years are not conclusive. The fact also that some of the cases mentioned in the Lismore group were not pronounced to be lepers during life would seem to throw some doubt upon the accuracy of the diagnosis.

St. Bartholomew's Hospital: the Luther Holden RESEARCH SCHOLARSHIP.-Mr. Harold W. Wilson, F.R.C.S. Eng., late house surgeon to St Bartholomew's Hospital, has been elected to the Luther Holden research scholarship in surgery for one year. The scholarship is of the annual value of 100 guineas and was founded by the bequest of the late Mr. Luther Holden, formerly surgeon to St. Bartholomew's Hospital and President of the Royal College of Surgeons of England. The holder of the scholarship must carry out such research work in surgery as may be approved by the electors either in the United Kingdom or abroad. Mr. Wilson has proposed to carry on research work in urinary surgery. 